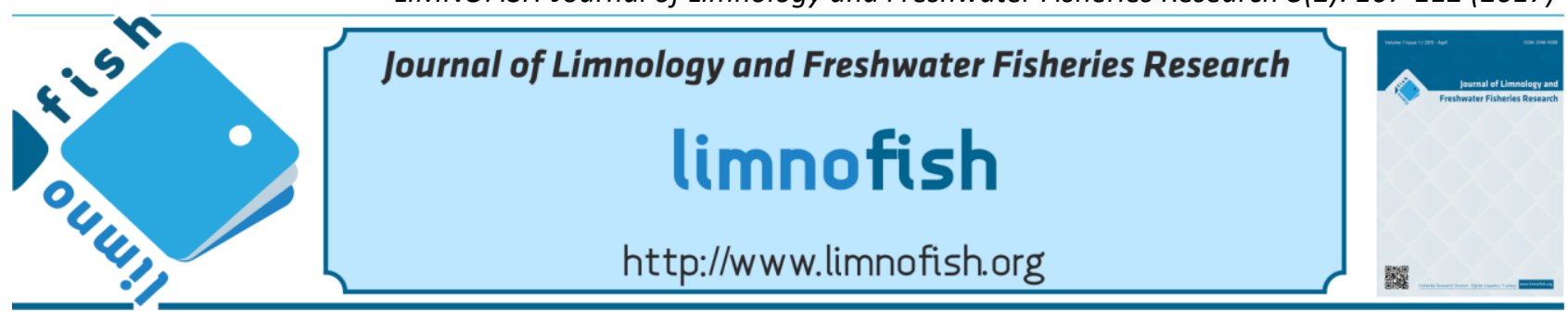

\title{
Descriptive osteology of Paracobitis persa Freyhof, Esmaeili, Sayyadzadeh \& Geiger, 2014, an endemic species from Kor River basin of Iran
}

\author{
Nasrin NIKMEHR ${ }^{\mathbb{D}}$, Soheil EAGDERI* ${ }^{*}$, Pariya JALILI ${ }^{(D)}$ \\ Department of Fisheries, Faculty of Natural Resources, University of Tehran, Karaj, Iran
}

\section{A B STRACT}

This study was carried out to provide a detailed osteological structure of the newly described crested loach, Paracobitis persa. For this purpose, ten specimens were collected from the Malsosjan spring, in the Kor River basin and fixed in 5\% buffered formalin. After clearing and staining, their skeletal structure was examined. The results were compared to the other members of the family Nemacheilidae particularly $P$. hyrcanica and $P$. iranica. Based on the results, $P$. persa can be distinguished from other members of this family by a combination of characters, including having lacking sesamoid ossifications, having six hypurals, a triangular-shaped lateral ethmoid with pointed ends, alveolar bony capsule, no contact between retroarticular and dental, lack of the pre-ethmoid-I and basibrancial-4.

Keywords: Skeleton, loach, Endorheic Kor basin, Iran

\section{ARTICLE INFO}

\section{SHORT COMMUNICATION}

$\begin{array}{lll}\text { Received } & : 21.10 .2016 \\ \text { Revised } & : 16.03 .2017 \\ \text { Accepted } & : 20.06 .2017 \\ \text { Published } & : 21.08 .2017\end{array}$

DOI: 10.17216/LimnoFish.334633

\section{* CORRESPONDING AUTHOR}

soheil.eagderi@ut.ac.ir

Tel : +989396954207

How to Cite

Nikmehr N, Eagderi S, Jalili P. 2017. Descriptive osteology of Paracobitis persa Freyhof, Esmaeili, Sayyadzadeh \& Geiger, 2014, an endemic species from Kor River basin of Iran LimnoFish. 3(2):107-112. doi: 10.17216/LimnoFish.334633

\section{Introduction}

Members of the genus Paracobitis Bleeker, 1863 are comparatively large-sized loaches with a long dorsal dermal crest, inhabiting freshwaters of western Asia (Banarescu and Nalbant 1964; Bănărescu and Nalbant 1995; Nalbant and Bianco 1998; Nguyen 2005; Prokofiev 2009; Min et al. 2010; JouladehRoudbar et al. 2015; Azimi et al. 2015a, 2015b, 2015c). There are twelve valid species of the genus Paracobitis in the world, which eleven of them are reported from Iran (Kottelat 2012; Coad 2016; Mousavi-Sabet et al. 2014; Freyhof et al. 2014; Jouladeh-Roudbar et al. 2015). According to Freyhof et al. (2014), Mousavi-Sabet et al. (2015), and Jouladeh-Roudbar et al. (2015a, 2015b), the valid Paracobitis species in Iran comprise P.atrakensis Esmaeili et al. (2014), P. basharensis Freyhof et al. (2014), P. hircanica Mousavi-Sabet et al. (2015), P. iranica Nalbant and Bianco, 1998, P. longicauda (Kessler, 1872), P. malapterura (Valenciennes, 1846), P. molavii Freyhof et al. (2014), P. persa Freyhof et al. (2014), $P$. rhadinaea (Regan, 1906) and $P$. vignai Nalbant and Bianco, 1998. However, Freyhof et al. (2014) believe that $P$. iranica is a synonym of P. malapterura.

Paracobitis persa, described from the Kor river drainage of Iran (Maloosjsn Spring and from Sivand River), is distinguished by having a prominent, irregularly shaped mid-lateral stripe, a shallow adipose crest, and the tube of the anterior nostril not fully overlapping the posterior nostril when folded back (Freyhof et al. 2014). There is little information is available about biological features of this recently described and threatened species (Esmaeili and Valavi 2016); therefore, the present study was conducted to provide a detailed osteological characteristics of this species. The results of this study can be used as a reference for its comparison with the other members of the genus Paracobitis. The results will also provide a basis for further phylogenetic study of Iranian members of the Paracobitis group using osteological data.

\section{Materials and Methods}

Ten specimens of $P$. persa (Fig. 1) with mean standard length of $62 \pm 10.5 \mathrm{~mm}$ were collected by electrofishing device from the Malsosjan Spring, in the Kor River basin (Fars Province, Sothern Iran). 
The collected specimens were anesthetized in $1 \%$ clove solution and then fixed in 5\% buffered formaldehyde. For osteological examination, the specimens were cleared and stained with alizarin red $\mathrm{S}$ and alcian blue based on Taylor and Van Dyke (1985). The left sides of the skeletal structures photographed using a scanner (Epson V600) equipped with a glycerol bath. The skeletal structure of specimens was observed and studied by a Leica MS5 stereomicroscope. The obtained images were drawn using CorelDrawX6 software. Nomenclature and abbreviation of the skeletal elements were done according to Prokofiev (2009, 2010), Azimi et al. (2015a, 2015b, 2015c) and Nikmehr and Eagderi (2016a, 2016b).

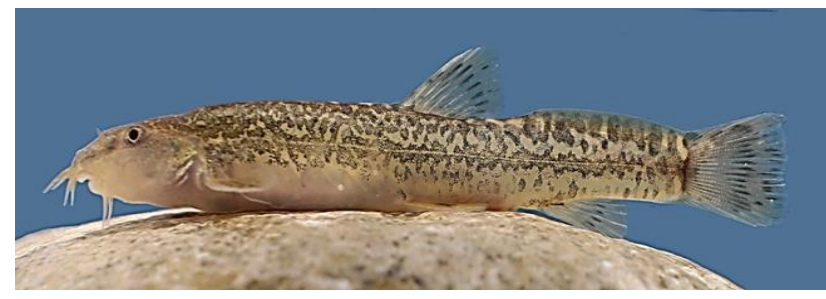

Figure 1. Lateral view of Paracobitis persa, Malsosjan Spring, Iran.

\section{Results}

The posterior part of the neurocranium is oval in shape and wider. The ethmoid region consists of the lateral ethmoid, supraethmoid-ethmoid, pre-ethmoid-II, kinethmoid and pre-vomer (Figs. 2a, b, c, 4). The supraethmoid-ethmoid is narrow with serrated rim posteriorly. This bone bears a groove on its dorsal face and is ventrally fused to the pre-vomer (Fig. 2a, b). The posterior edge of the lateral ethmoid is concaved. The unpaired cylindrical kinethmoid possesses two mid-lateral processes (Fig. 3a). The pre-ethmoid-II is short and cylindrical in shape; its middle part is slightly curved. This bone is connected to the pre-palatine laterally, to the anterior part of the pre-vomer posteriorly and to the maxilla anteriorly.

The orbital region comprises the frontals, parasphenoid, pterosphenoids, and orbitosphenoids. The frontal is the largest bony element of the skull roof; it is connected to the orbitosphenoid anterolaterally. The parietals, frontals, and supraoccipital enclose the fontanel. The parasphenoid is the longest bone in the ventral face of the neurocranium; its anterior and posterior ends are bifurcated. The pterosphenoid is connected to the frontal dorsally and to the sphenoid postero-laterally; its posterior margin is curved, forming a cavity along with the prootic and parasphenoid (Fig. 2c). The orbitosphenoid is connected to the lateral-ethmoid ventrally, to the parasphenoid laterally, and to the pterosphenoid posteriorly.

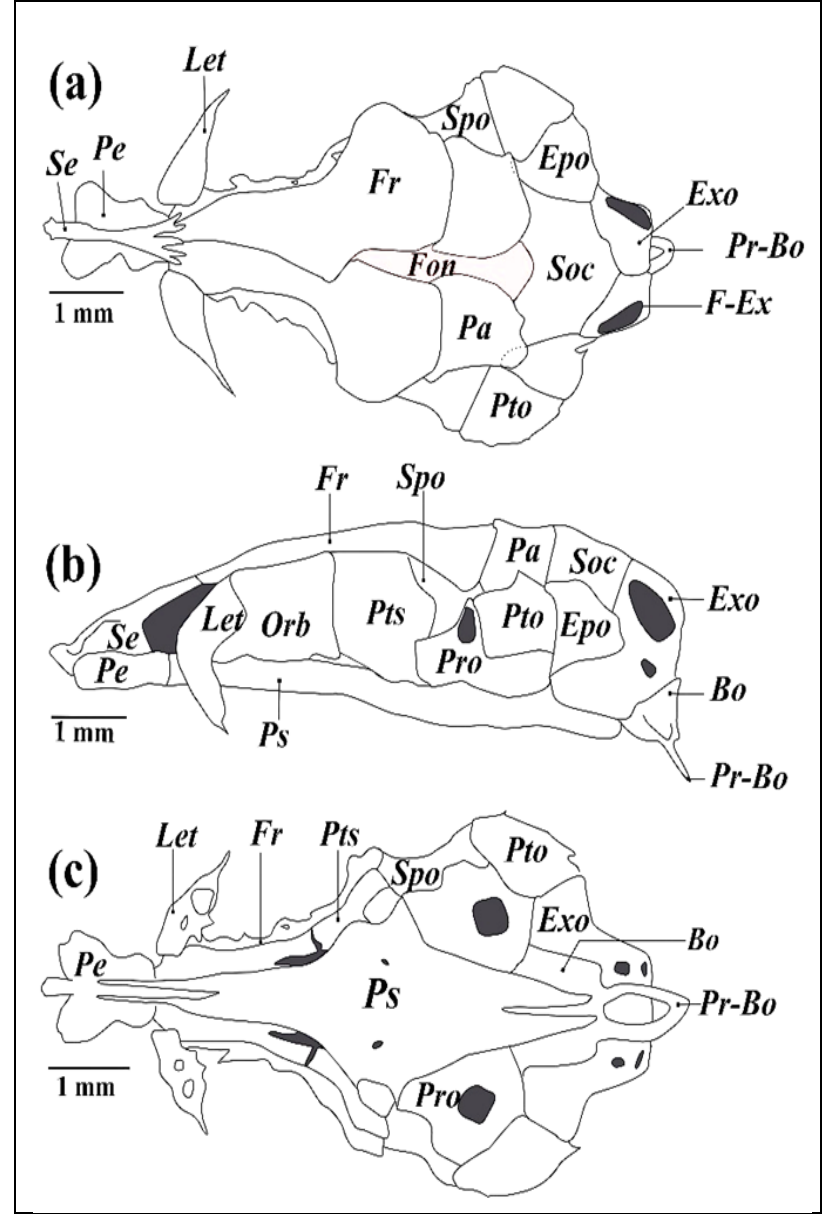

Figure 2. (a) Dorsal (b) lateral, (c) ventral views of the neurocranium in Paracobitis persa. Fon: fontanel; F-Ex: foramen exoccipital; Pr-Bo: basioccipital process; Bo: basioccipital; Epo: epiotic; Exo: exoccipital; Fr: frontal; Let: lateral ethmoid; Orb: orbitosphenoid; Pa: parietal; Pe: pre-vomer; Pro: prootic; Ps: parasphenoid; Pto: pterotic; Pts: pterosphenoid; Se: supraethmoid-ethmoid; Soc: supraoccipital; Spo: sphenotic. ethmoid is narrow with serrated rim posteriorly. This bone bears a groove on its dorsal face and is ventrally fused to the pre-vomer (Fig. 2a, b). The posterior edge of the lateral ethmoid is concaved. The unpaired cylindrical kinethmoid possesses two mid-lateral processes (Fig. 3a). The pre-ethmoid-II is short and cylindrical in shape; its middle part is slightly curved. This bone is connected to the pre-palatine laterally, to the anterior part of the pre-vomer posteriorly and to the maxilla anteriorly.

The otic region includes the parietal, epiotic, sphenotic, pterotic and prootic. The parietal is approximately square-shaped and its posterior margin covers the anterior part of the epiotic (Fig. 2a). The pterotic is quarter-circle in shape connecting to the epiotic and sphenotic dorso-laterally and to the prootic and exoccipital ventro-laterally (Fig. 2a, c). The epiotic is oval-shaped and bears a posterior process (Fig. 2a), situating between the pterotic and supraoccipital. The sphenotic forms the lateral wall of the neurocranium (Fig. 2b) and is connected to the prootic ventrally and to the parietal postero-dorsally. The two prootics are connected to each other ventrally and to the parasphenoid dorsally by a 
descending process. The prootic bears two large pores on its anterior part.

The occipital region is composed of the supraoccipital, exoccipitals and basioccipital. The supraoccipital is pentagon in shape in dorsal view and its anterior margin is involved in the formation of the fontanel. In the ventral part of the basioccipital, a pharyngeal process is present (Fig. 2c). The anterior hyomandibular facet is formed by the pterosphenoid, sphenotic and prootic; and the posterior one by the sphenotic and pterotic. The fontanel is covered by connective tissue and extended longitudinally.

The upper jaw is made up of the maxilla and premaxilla. The maxillary possesses a midlateral ascending and an anterior descending processes; it has also a distal process on its dorsal border. The premaxilla is a thin L-shaped bone and its vertical portion is narrower; the horizontal part has a process on its middle-anterior margin. The lower jaw is composed of the dentary, articular, retroarticular and coronomeckelian (Fig. 3b). The coronomeckelian is present on the medial face of the lower jaw situated in the dorsal part of the articular. The dentary is the largest element of the lower jaw possessing the narrow ramus dentalis and a wide coronoid process.

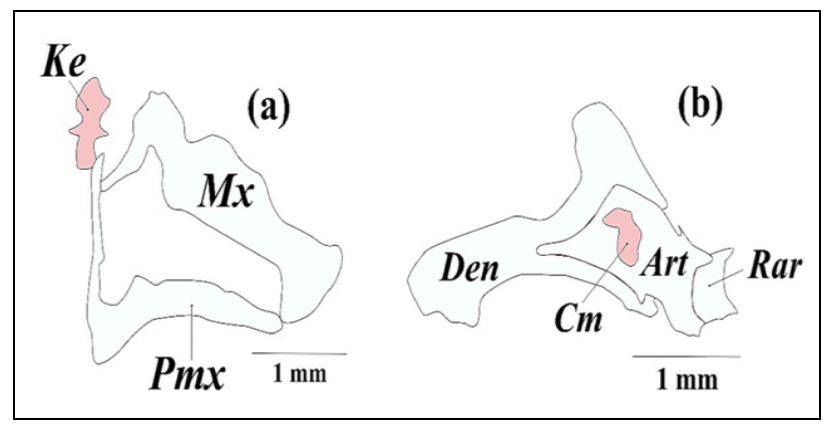

Figure 3. (a) Upper and (b) lower jaw (medial face) of Paracobitis persa. Art: articular; $\mathrm{Cm}$ : coronomeckelian; Den: dentary; Ke: Kinethmoid; Mx: Maxilla; Pmx: Premaxilla; Rar: retroarticular.

The suspensorium is formed by the hyomandibular, ectopterygoid, endopterygoid, metapterygoid, autopalatine, symplectic and quadrate (Fig. 4). The hyomandibular is almost triangular in shape and its dorsal part is wider. It bears two dorsal condyles which are articulated to the neurocranium. The ventral part of the hyomandibular is connected to the interhyal. The ectopterygoid, endopterygoid, metapterygoid, symplectic and quadrate form a bony complex connecting to the anterior part of the neurocranium via the auto-palatine. The ventral edge of the ectopterygoid is jagged. The endoptrygoid has a mid-dorsal protuberance that is connected to the metaptrygoid and ectoptrygoid ventrally; this bone articulated to the auto-palatine by an anterior condyle. The metapterygoid is roughly rectangular in shape; its lateral part is caved and its ventral part has a pointed process. The quadrate bears a pointed and stretched abdominal process bending posteriorly. The symplectic is a triangular bone located between the quadrate and hyomandibular.

The opercular series includes the opercle, preopercle, subopercle, and interopercle (Fig. 4). The opercle is a large and triangular bone, and bears a rodshaped process antero-dorsally for connection to the levator operculi muscle. The ventral margin of the opercle is connected to the subopercle that is narrow and strip-like. The interopercle is a narrow bone; it is pointed at its two ends. The posterior part of the preopercle bears two processes.

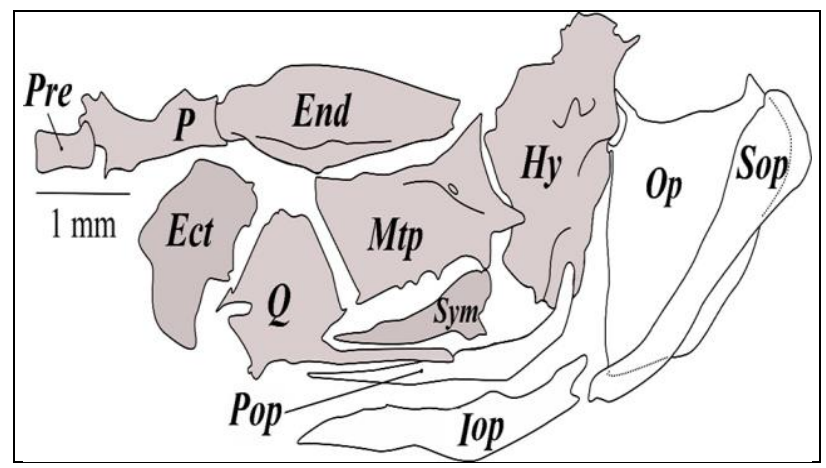

Figure 4. Lateral view of suspensorium and opercle series of Paracobitis persa. Ect: ectopterygoid; End: endopterygoid; Hy: hyomandibulare; Io: interopercle; Mtp: metapterygoid; Op: opercle; P: auto-palatine; Po: preopercle; Pre: pre-ethmoid-II; Q: quadrate; So: subopercle; Sym: symplecic.

The branchial apparatus includes five pairs of the ceratobranchials, four pairs of the epibranchials, three pairs of the hypobranchials and basibranchials and two paired infrapharyngobranchial (Fig. 5a). The ceratobranchials are the largest element and fifth one is modified as the pharyngeal teeth. The third basibranchial is longer than the two others. The epibranchial-4 has a ventral plate-like protrusion. The second hypobranchial is attached to the first basibranchial anteriorly.

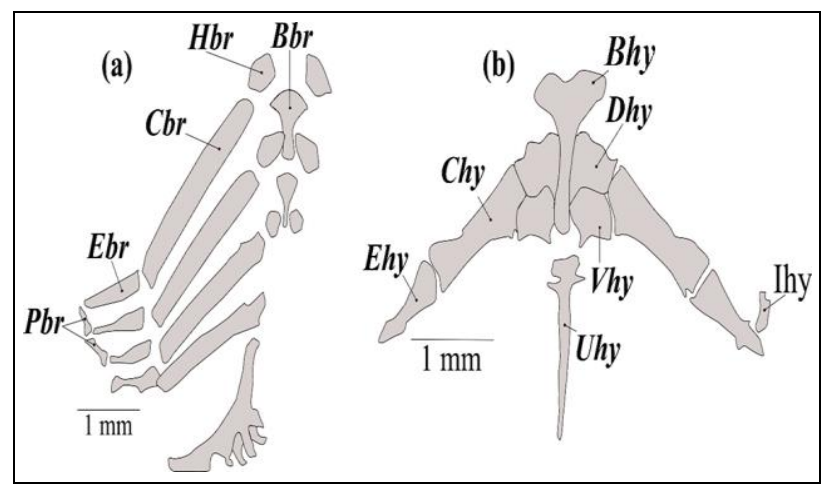

Figure 5. Branchial apparatus (a) and Hyoid arch (b) of Paracobitis persa. Bbr: basibranchial; Cbr: ceratobranchial; Ebr: epibranchial; Hbr: hypobranchial; Pbr: inphrapharyngobranchial; Bhy: basihyal; Chy: ceratohyale; Dhy and Vhy: dorsal and ventral hypohyal; Epi: epihyal; Ihy: interhyal; Uhy: urohyal. 
The hyoid arch consists of the epihyals, hypohyals, ceratohyals, urohyal, basihyal and three pairs of the branchiostegal rays. The urohyal is narrow and bears two ventral and dorsal parts; its dorsal part is blade-like and perpendicular and the ventral part is bifurcated. The basihyal is a T-shaped bone with a small anterior fossa (Fig. 5b). The paired ventral and dorsal hypohyal are tightly connected together. The ceratohyal is the largest bone of this arch situating between the hypohyal and epihyal. The first and second branchiostegal are positioned, respectively, in the middle of the ceratohyal and at the junction of the ceratohyal and epihyal. The third one is positioned in the middle of the epihyal.

The pectoral girdle consists of the cleithrum, supracleithrum, coracoid, mesocoracoid, scapula, posttemporal, supratemporal and radials (Fig. 6a). The cleithrum bears two wide descending and ascending portions; its ventral part bears an anteromedial downward process connecting to the anterior part of the coracoids. Also, it has a dorsal process on its ascending part for connecting to the supracleithrum. The supratemporal is a small bone locating on the anterior margin of the posttemporal. The posttemporal is thin and long, and located between the supracleithrum and supratemporal. The anterior part of the coracoid is narrower. The anterior parts of the cleithrum and coracoid are connected; the posterior part of the coracoid bears an ascending process for connecting to the mesocoracoid. The dorsal part of the mesocoracoid is broadened and attached to the medial side of the cleithrum. A semicircular scapula is located between cleithrum and coracoid bones; this bone bears a large foramen.

The pelvic girdle includes the paired pelvic bone, pelvic splint and radials (Fig. 6b). The anterior part is narrower. There is a U-shaped hollow on the anterior margin of the pelvic bone. The two L-shaped pelvic splints are located at the postero-lateral side of the pelvic bone. There are three radial bones positioning along the postero-lateral side of the ventral bone.

The Weberian apparatus is formed by four anterior centra with their ossicles, including the tripus, intercalarium, scaphium and claustrum (Fig. 7a). The claustrum is circular in shape and situated at the dorsal side of the scaphium. The intercalarium is small and positioned between the scaphium and Y-shaped tripus. The first centrum has two lateral processes which are ligamentously connected to the pectoral girdle. The second, third, and fourth centra participate in the formation of bony capsule. The second and third centra are fused together. The parapophysis of the forth centrum is modified and bears processes to forms the posterior part of the bony capsule. In the lateral part of the bony capsule, two openings are observed that anterior one is larger. The surface of the bony capsule is vascular. The right and left lobes of the bony capsule are symmetrical and divided by the manubrium (Fig. 7a).

The dorsal fin bears 4 unbranched, $71 / 2$ branched rays, 8 pterygiophores and one stay bone. The first pterygiophore is bifurcated and the largest elements, situating in the front of the $14^{\text {th }}$ centrum (Fig. 7b). A triangular stay bone supports the last branched ray.

The Anal fin consists of 3 unbranched, 51/2 branched rays, 6 pterygiophores and one stay bone (Fig. 7c). The first pterygiophore is bifurcated situating in the front of the $26^{\text {th }}$ vertebra.

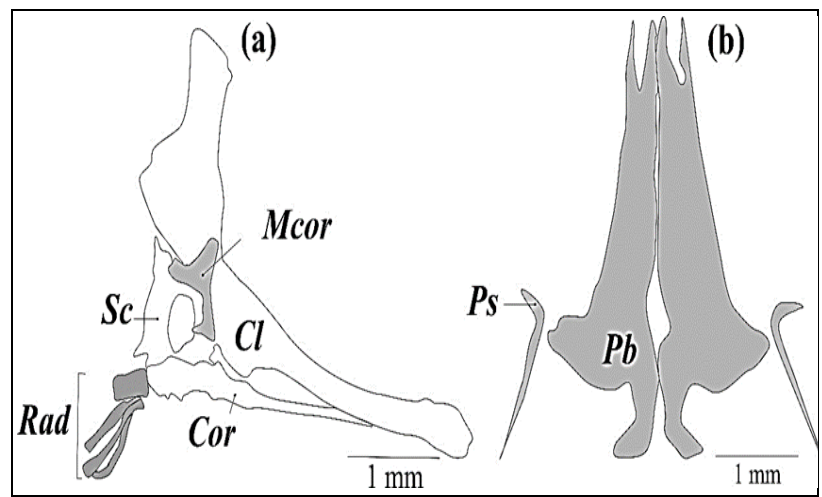

Figure 6. Pectoral girdle (a) and pelvic girdle (b) of Paracobitis persa. $\mathrm{Cl}$ : cleitherum; Cor: coracoid; Mcor: mesocoracoid; Rad: ossified pectoral radial; Sc: scapula; Ps: pelvic splint; R: radials.

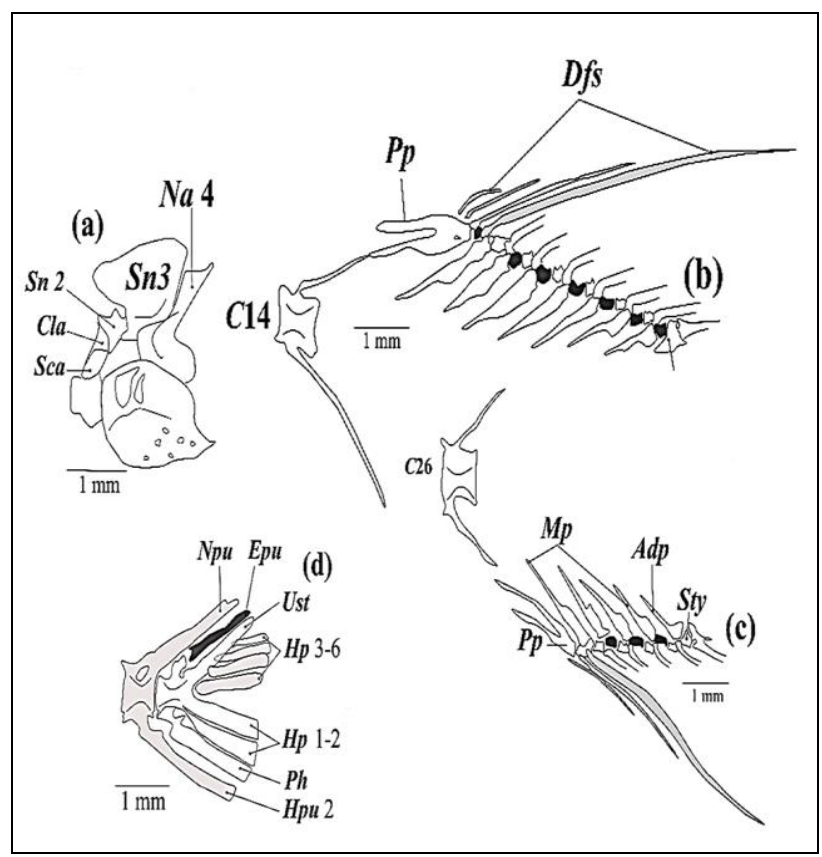

Figure 7. Swim bladder capsule (a), dorsal (b), anal (c) and caudal (d) fin skeleton of Paracobitis persa. Adp: anal distal pterygiophore; C $14-26$ : $14^{\text {th }}$ and $26^{\text {th }}$ centrum; Dfs: dorsal fin spine; Mp: mesial pterygiophore; $\mathrm{Ph}$; parhyporal; Pp: pterygiophore; Sty: stay; Epu: epural; Hp1-5: hypural plates; Npu_2: neural processes of the second preural centrum; Hpu_2: hemal processes of the second preural centrum; Ust: pleurostile; Cla: claustrum; Na4: neural arch 4; Sca: scaphium; Sn 2-3: supraneural 2 and 3. 
The caudal skeleton consists of four centra with the epural, parahypural, pleurostyle, uroneural and six hypurals bones (Fig. 7d). The pleurstyle is fused to the last centrum. The hypural-1 reaches to the ventral edge of the terminal centrum and not connected to the parahypural. The epural is a long, narrow and free bone, connected to the pleurostyle ventrally by connective tissue. The neural process of the $4^{\text {th }}$ centrum become wide and bifurcated.

\section{Discussion}

The present study provided a detailed skeletal description of $P$. persa. In this species, similar to Oxynoemacheilus kiabii (Mafakheri et al. 2014), O. bergianus (Jalili and Eagderi 2014), Sasanidus kermanshahensis (Mafakheri et al. 2015), Paraschistura nielseni (Azimi et al. 2015a) and $P$. cristata (Azimi et al. 2015b) and P. hircanica (Azimi et al. 2014), the junction of the lateral ethmoid is at the anterior margin of the orbitosphenoid; whereas according to Prokofiev (2010), the lateral ethmoid of loaches is stationarily jointed to the supraethmoid-ethmoid.

There is no preethmoid-I in P. persa, O. kiabii (Mafakheri et al. 2014), O. bergianus (Jalili and Eagderi 2014), S. kermanshahensis (Mafakheri et al. 2015), P. nielseni (Azimi et al. 2015a), P. cristata (Azimi et al. 2015b) and P. hircanica (Azimi et al. 2014) versus presence of the pre-ethmoid-I in the genera of Lefua, Oreonectes, Yunnanilus, Eonemachilus, Micronoemacheilus, Hedinichthys, Orthrias, and Triplophysa (Prokofiev 2010). The lateral ethmoid is oriented horizontally and its middle part is wider in P. persa, whereas in P. hircanica, it is L-shaped having a process oriented anteriorly (Azimi et al. 2014); this process is absent in P. iranica (Nikmehr and Eagderi 2016a).

There is no sesamoid ossification in P. persa, similar to $P$. hircanica, but in $O$. kiabii (Mafakheri et al. 2014), O. bergianus (Jalili and Eagderi 2014), S. kermanshahensis (Mafakheri et al. 2015) and P. cristata (Azimi et al. 2015b), a sesamoid ossification is present. However, according to the Prokofiev (2009, 2010), the sesamoid ossifications are present in the members of the genus Paracobitis as well as Dzihunia amudarjensis and Oxynoemacheilus angorae.

The $4^{\text {th }}$ basibranchial is absent in the $P$. persa similar to $P$. hircanica and the other members of the genus Paracobitis (Prokofiev 2009). However, in O. kiabii (Mafakheri et al. 2014), O. bergianus (Jalili and Eagderi 2014), S. kermanshahensis (Mafakheri et al. 2015) and P. nielseni (Azimi et al. 2015a), it is present.

In $P$. iranica, the frontal is wider (Nikmehr and Eagderi 2016a) than that of $P$. hircanca (Azimi et al.
2014) and P. persa. Unlike the members of the genera Metaschistura, Paraschistura, Oxynoemacheilus and Iskandaria (Prokofiev 2010), there is a bony bridge between the parietal and pterotic in $P$. persa. In $P$. hircanica, the posterior part of the maxilla is wider (Azimi et al. 2014) than that of P. persa.

The number of unbranched and branched rays of the anal fin is 3 and 51/2, respectively in $P$. persa, and $P$. hyrcanica; whereas they are $3 \frac{1}{2}$ and 5 in $P$. iranica (Azimi et al. 2014), respectively. Furthermore, the number of unbranched and branched rays of the dorsal fin is 3 and 7 in P. iranica (Nikmehr and Eagderi 2016a), but they are 4 and $71 / 2$ in $P$. hyrcanica and $P$. persa, respectively.

The neural processes of the $3^{\text {rd }}$ centrum has three processes in P. hircanica (Azimi et al. 2014), whereas that of $P$. iranica (Nikmehr and Eagderi 2016a) and $P$. persa has no dorsal process. According to Prokofiev (2009), there are 6 hypurals in the genus Paracobitis as observed in $P$. persa and $P$. iranica (Nikmehr and Eagderi 2016a), whereas there is five hypurals present in P. hircanica (Azimi et al. 2014). However, six hypurals are present in $O$. bergianus (Jalili and Eagderi 2014).

As a result, $P$. persa is distinguished from other members of the family Nemacheilidae, particularly $P$. hyrcanica and $P$. iranica by a combination of characters, including having lacking sesamoid ossifications, having six hypurals, a triangular-shaped lateral ethmoid with pointed ends, alveolar bony capsule, no contact between retroarticular and dental, lack of the pre-ethmoid-I and basibranchial-4.

\section{References}

Azimi H, Mousavi-Sabet H, Eagderi S. 2015a. Osteological characteristics of Paraschistura nielseni (Nalbant \& Bianco, 1998) (Cypriniformes: Nemacheilidae). Iran J Ichthyol. 2(3):155-164

Azimi H, Mousavi-Sabet H, Eagderi S, Vatandoust S. 2015b. Osteological characteristics of Turkmenian stone loach, Paraschistura cristata (Cypriniformes: Nemacheilidae). Int J Aquat Biol. 3(5):290-300.

Azimi H, Mousavi-Sabet H, Eagderi S, Vatandoust S. 2014. Osteology of Hyrcanian crested loach, Paracobitis hircanica (Pisces, Nemacheilidae). Our Nature. 13(1):8-18. doi: 10.3126/on.v13i1.14203

Bănărescu P., Nalbant T. 1964. Süßwasserfische der Türkei. 2. Teil Cobitidae. Mitteilungenaus dem hamburgischen Zoologischen Museum und Institute. 61:159-201.

Bănărescu P, Nalbant T. 1995. A generical classification of Nemacheilinae with description of two new genera (Teleostei: Cypriniformes:Cobitidae). ravaux du Muséum d'Histoire Naturelle Grigore Antipa, Bucurešti. 35:429-496. 
Bleeker P. 1863. Sur les genres de la famille des Cobitioïdes. Nederlands Tijdschrift van Dierkunde. $1: 361-368$

Coad BW. 2016. Fresh water fishes of Iran. Available from http://www.briancoad.com.

Esmaeili HR., Sayyadzadeh G, Özulug M, Geiger M, Freyhof J. 2014. Three new species of Turcinoemacheilus from Iran and Turkey (Teleostei: Nemacheilidae). Ichthyol Explor Fres. 24(3):257-273.

Esmaeili HR, Valavi H. 2016. Threatened fishes of the world: Paracobitis persa Freyhof, Esmaeili, Sayyadzadeh \& Geiger, 2014. (Teleostei: Nemacheilidae). FishTaxa. 1(1):29-34.

Freyhof J, Esmaeili HR, Sayyadzadeh G, Geiger M. 2014. Review of the crested loaches of thegenus Paracobitis from Iran and Iraq with the description of four new species (Teleostei: Nemacheilidae). Ichthyol Explor Fres. 25(1):11-38.

Jalili P, Eagderi S. 2014. Cephalic osteology of Safidrud stone loach Oxynoemacheilus bergianus. Iran J Anim Res. 28(1):21-34

Jouladeh-Roudbar A, Eagderi S, Esmaeili HR. 2015a. Fishes of the Dasht-e Kavir basin of Iran: an updated checklist. Int J Aquat Biol. 3(4):263-273.

Jouladeh-Roudbar A, Vatandoust S, Eagderi S, JafariKenari S, Mousavi-Sabet H. 2015b. Freshwater fishes of Iran; an updated checklist. AACL Bioflux. $8(6): 855-909$.

Kottelat M. 2012. Conspectus cobitidum: an inventory of the loaches of the world (Teleostei: Cypriniformes: Cobitoidei). Raffles Bull. Zool. 26(Suppl): 1-199.

Mafakheri P, Eagderi S, Farahmand H, Mousavi-Sabet H. 2014. Osteological structure of Kiabi loach, Oxynoemacheilus kiabii (Actinopterygii: Nemacheilidae). Iran J Ichthyol. 1(3):197-205.

Mafakheri P, Eagderi S, Farahmand H, Mousavi-Sabet H. 2015. Descriptive osteology of Oxynoemacheilus kermanshahensis (Bănărescu and Nalbant, 1966) (Cypriniformes, Nemacheilidae). Croat J Fish. 73(3):115-123. doi: 10.14798/73.3.840

Min R Chen, XY, Yang JX. 2010. Paracobitis nanpanjiangensis, a new loach (Balitoridae:
Nemacheilinae) from Yunnan, China. Env Biol Fish. 87(3):199-204. doi: 10.1007/s10641-010-9587-Z

Mousavi-Sabet H, Gharaei A, Nasrollahzade A, Habibi A, Eagderi S. 2014. Redescription of Paracobitis rhadinaea (Regan, 1906) from Sistan Basin, Iran (Teleostei: Nemacheiliidae). Int. J Aquat Biol. 2(5): 286-291.

Mousavi-Sabet H, Sayyadzadeh G, Esmaeili HR, Eagderi S, Patimar R, Freyhof J. 2015. Paracobitis hircanica, a new crested loach from southern Caspian Sea basin (Teleostei: Nemacheilidae). Ichthyol Explor Fres. 25(4):339-.346.

Nalbant T, Bianco P. 1998. The loaches of Iran and adjacent regions with description of six new species (Cobitoidea). Ital J Zool 65(Suppl):109-123. doi: 10.1080/11250009809386803

Nikmehr N, Eagderi S. 2016a. Descriptive osteology of Paracobitis iranica Nalbant and Bianco, 1998 (Cypriniformes, Nemacheilidae) from Namak Lake Basin of Iran. Acta Biologica Turcica. 29(2): 47-54.

Nikmehr N, Eagderi S, Poorbagher H, Farahmand H. 2016b. The complete description of the skeletal structure of Hafez loach, Turcinoemacheilus hafezi (Cypriniformes, Nemacheilidae). Int J Aquat Biol. 4(2):117-124.

Nguyen VH. 2005. Freshwater fishes of Vietnam. v. $2: 760 \mathrm{p}$.

Prokofiev AM. 2009. Problems of the classification and phylogeny of Nemacheiline loaches of the group lacking the preethmoid I (Cypriniformes: Balitoridae: Nemacheilinae). J Ichthyol. 49(10):874-898. doi: 10.1134/S0032945209100051

Prokofiev AM. 2010. Morphological classification of loaches (Nemacheilinae). J Ichthyol. 50(10):827-913 doi: 10.1134/S0032945210100012

Taylor WR, Van Dyke GC. 1985. Revised procedures for staining and clearing small fishes and other vertebrates for bone and cartilage study. Cybium. 9(2):107-119. 